\title{
Estrategias para el enfrentamiento del cólera. La experiencia chilena desde una perspectiva de salud pública
}

\author{
M. Teresa Valenzuela B., Hugo Salinas P., Marcela Cárcamo I., Jaime Cerda L. y Gonzalo Valdivia C.
}

\section{Strategies for dealing with cholera disease. A public health perspective of the Chilean experience}

During the latest Latin American epidemic of cholera (1991), more than 70,000 cases were identified and over 6,000 deaths occurred. Cholera started in Peru and expanded to the rest of Latin American countries, including Chile. Compared to Peru, the epidemic in Chile had minor consequences due to the strategies adopted by the National System of Health Services, together with other public institutions. These strategies included the establishment of a National Committee for Cholera, strategic planning of health services, strengthening of epidemiologic surveillance systems and of clinical and environmental laboratories, education of the population, and preventive strategies, among others. Maintenance of environmental health measures and the population's collaboration are essential to avoid future emergence of this disease.

Key words: Cholera, public health strategies, epidemiologic surveillance.

Palabras clave: Cólera, vigilancia epidemiológica, estrategias de salud pública.

\section{Introducción}

$\mathrm{E}$ $\mathrm{n}$ el transcurso de la historia, poblaciones de todo el mundo han sido afectadas esporádicamente por brotes de cólera ${ }^{1}$. Las características de rápida transmisión y alta agresividad del agente patógeno causante de esta enfermedad han determinado la ocurrencia de episodios caracterizados por altas tasas de morbilidad y mortalidad ${ }^{2}$. Durante la mayor parte del siglo XX el cólera estuvo confinado principalmente en Asia, particularmente Indonesia y el Golfo de Bengala ${ }^{2}$. Hacia fines del siglo $\mathrm{XX}$, en América Latina el cólera era considerada una enfermedad del pasado; sin embargo, en 1991 se presentó en forma explosiva, dando inicio a una epidemia. En el mes de enero de aquel año se notificaron los primeros casos en las ciudades peruanas de Chancay y Chimbote ${ }^{3,4}$. En los meses siguientes, la epidemia afectó a Ecuador y Colombia, extendiéndose luego al oriente a Brasil, por el sur a Chile y por el norte a México. Hacia fines de 1991 estaban afectados 15 países de las Américas ${ }^{2,4-8}$, notificándose más de 730.000 casos de la enfermedad y más de 6.300 fallecimientos ${ }^{5}$. La incidencia alcanzada por el cólera en la Región de las Américas durante 1991 fue la más alta registrada en cualquier época y continente, llegando a ser la más relevante en todo el curso de la séptima pandemia ${ }^{5}$. Teniendo en cuenta estos antecedentes, en nuestro país fue necesario implementar rápidamente un plan de acción, cuyo objetivo fue la ejecución de estrategias de prevención y control de la enfermedad, todas ellas orientadas a evitar su diseminación. Considerando el corto tiempo en que Chile logró controlar la epidemia de cólera de 1991, juzgamos relevante traer al presente dicha experiencia, incluyendo el componente de planificación estratégica y el enfoque intersectorial utilizado. Esta experiencia constituye un ejemplo de modelo para el control y prevención de futuras epidemias en nuestro país. Este artículo detalla la organización del sistema de vigilancia epidemiológica utilizado, aspectos referentes a educación en salud, medidas de control de infecciones intrahospitalarias, estrategias de control sobre los viajes internacionales y puestos fronterizos y la planificación estratégica integrada desplegada en nuestro país.

\section{Vigilancia epidemiológica}

Desde el momento que fueron notificados los primeros casos de cólera en Perú, comenzó la alerta epidemiológica en Chile. Las primeras medidas de orden general adoptadas en nuestro país fueron la constitución de una Comisión Nacional del Cólera y la realización de un diagnóstico de situación acabado, desde una perspectiva clínica y ambiental, de los recursos disponibles y del grado de capacitación de los equipos de salud. De igual forma, se inició el diseño de un sistema de vigilancia epidemiológica y control del cólera enfocado al hombre y al ambiente ${ }^{5}$. La Comisión Nacional del Cólera se subdividió en varias subcomisiones que analizaron las diferentes aristas de la epidemia, para así dar una rápida respuesta a la población. Uno de los aspectos que logró resolverse
Universidad de Los Andes, Santiago, Chile.

Facultad de Medicina (MTVB, MCI). Hospital Clínico de la Universidad de Chile, Santiago (HSP). Pontificia Universidad Católica de Chile. Facultad de Medicina, Departamento de Salud Pública (JCL, GVC).

Recibido: 14 de abril de 2010 Aceptado: 28 de abril de 2010

Correspondencia a: María Teresa Valenzuela Bravo mtvalenzuela@uandes.cl 
con mayor prontitud tuvo relación al diagnóstico de Vibrio cholerae gracias a la existencia de un cepario en el Instituto de Salud Pública (ISP), de modo que las técnicas de laboratorio de identificación y aislamiento del agente causal $^{5}$ fueron validadas y transferidas a través del Sistema Nacional de Laboratorios Clínicos y del Ambiente.

Por su parte, la vigilancia epidemiológica contó con tres líneas de acción. La primera fue la construcción de una curva de consultas por diarrea tanto para la población infantil como adulta. Este método sirvió como una señal de alerta en caso que las consultas se incrementaran en 50\% de una semana a otra o en caso de existir una diferencia en el número de episodios de diarrea en niños respecto a los adultos. La segunda fue una búsqueda activa de $V$. cholerae en muestras de coprocultivos a los pacientes con cuadros diarreicos. Por último, la tercera línea de acción correspondió a la notificación de los casos sospechosos en una ficha especialmente diseñada para tales efectos, definiéndose como tal a los pacientes con un cuadro diarreico y deshidratación de cualquier grado (leve, moderada o grave $)^{5,9}$. Todo examen de coprocultivo positivo en el nivel local era enviado para su confirmación al ISP. Si a nivel local este examen era negativo, pero el cuadro clínico era compatible con cólera y/o existían antecedentes de nexo epidemiológico o de procedencia desde lugares de riesgo, se tomaba un examen para detectar anticuerpos vibriocidas, el cual era realizado por el ISP ${ }^{5,9}$.

Con respecto a la vigilancia y control ambiental del cólera, la campaña se orientó principalmente hacia dos objetivos: el primero era retrasar la diseminación del agente causal en el territorio nacional, y el segundo era interrumpir las vías de transmisión ${ }^{5,9}$. Para ello, se realizó una vigilancia sanitaria de los sistemas de abastecimiento de agua potable, de las plantas de tratamiento de aguas servidas, así como vigilancia y control de la calidad sanitaria de los alimentos y eliminación de focos de insalubridad. Por otro lado, hubo una sustitución de todos los cultivos de hortalizas y frutas que crecen a ras de suelo por otro tipo de plantaciones en aquellas tierras regadas por aguas servidas o contaminadas y/o que no cumplían con la norma de calidad para aguas de riego, tarea realizada en colaboración con el Ministerio de Agricultura. Un importante trabajo fue la vigilancia epidemiológica en terreno; ello incluía actividades tales como entrevistas epidemiológicas, encuestas, visitas epidemiológicas y la difusión de la información ${ }^{5,8,9}$.

\section{Intercambio entre la bacteria y el humano}

Los factores que condicionaron el comportamiento del cólera en los períodos siguientes a su introducción en el país fueron el saneamiento básico adecuado, los hábitos y alimentación higiénica y el desarrollo social y cultural. Se implementaron diferentes estrategias de eliminación del cólera, por ejemplo, la filtración y desinfección de sumi- nistros públicos de agua, tratamiento de aguas residuales y promoción de una mejor higiene personal. Experiencias internacionales indican que ningún país había podido eliminar la enfermedad sin adoptar estas medidas ${ }^{2,5,9}$.

\section{Higiene en la comunidad}

Para prevenir la presencia de brotes de cólera en el país se implementaron amplios programas de educación sanitaria sobre medidas higiénicas, cuyo objetivo principal fue el llevar a la práctica un cambio de conducta sanitaria en la población. Estos programas fueron difundidos por diversos medios de comunicación (periódicos, televisión, radio, folletos, etc). La campaña estuvo orientada al conocimiento de la bacteria (características, formas y vías de contagio) y de los cuadros diarreicos (síntomas y signos, peligros potenciales), proporcionándose indicaciones sobre hábitos de higiene tales como el lavado de manos, la cocción, conservación y almacenamiento de alimentos y la eliminación de basura. Gracias a estas acciones, Chile logró niveles muy bajos de la enfermedad. Sin embargo, sólo se conseguiría erradicar el cólera cuando la población cumpliese regular y constantemente con las medidas propuestas, sobre todo en lo que respecta a hábitos de higiene y alimentación ${ }^{5,9}$.

\section{Control de las infecciones intrahospitalarias}

Pese a que el cólera no es una enfermedad que se transmite fácilmente por contacto directo, el personal hospitalario debió mantener precauciones de aislamiento entérico, con la finalidad de prevenir su propagación. En caso de que existiera la posibilidad de contaminación con deposiciones, se requirió el uso de delantales de aislamiento, guantes, lavado de manos antes y después de la atención directa al paciente y de artículos contaminados, así como educar a los pacientes ${ }^{5,9}$. Todos los casos fueron tratados con terapias de hidratación oral o parenteral y antimicrobianos y se procedió a la vigilancia de los contactos del caso índice, a partir del quinto día de la última exposición. El uso de vacunas no fue recomendado debido a que éstas poseen un efecto protector limitado (3-6 meses de protección al 50\% de las personas inmunizadas) $)^{8,10,11}$.

\section{Viajes internacionales y controles fronterizos}

Con el fin de disminuir el riesgo de diseminación del agente causal en el territorio nacional, particularmente en relación con los buses internacionales provenientes del Perú, fueron habilitados sitios de descarga controlados en puntos estratégicos de las actuales regiones de Arica y Parinacota (XV) y Metropolitana (RM). De igual forma, se habilitaron a nivel nacional sumideros de descarga en terminales rodoviarios. Medidas similares fueron adoptadas en puertos y en el aeropuerto internacional de Santiago. Toda persona proveniente de zonas infectadas que ingresó al país fue encuestada por personal de salud, 
además de ser observada durante un período de tiempo para detectar signos clínicos de infección ${ }^{12}$.

\section{Planificación estratégica en el control y erradicación de cólera en Chile}

Como ya fuera mencionado, la Comisión Nacional del Cólera fue el organismo encargado de coordinar todas las acciones intersectoriales tendientes a montar una pronta respuesta ante los problemas de salud que enfrentaba el país. Además, proporcionaba elementos técnicos para el trabajo intersectorial con otros ministerios y con la autoridad central ${ }^{5}$. Se adoptó un esquema centralizado de compras de medicamentos, sales de hidratación, insumos, equipos y material de laboratorio. La distribución de éstos a lo largo del país se realizó a través de la Central de Abastecimientos del Ministerio de Salud, en base al riesgo y déficit relativo de recursos materiales y humanos, detectados a través de un diagnóstico de situación de los diferentes Servicios de Salud ${ }^{5}$. Se estableció también un intercambio rápido de información entre los países afectados y se prepararon y difundieron normas técnicas de control y tratamiento ${ }^{5}$. Se realizaron talleres de planificación estratégica en cada una de las regiones del país, lo que permitió hacer el diagnóstico de su situación en términos de fortalezas, debilidades, oportunidades y amenazas, para enfrentar con éxito una situación de este tipo ${ }^{5}$.

Una de las actividades realizadas para prevenir y evitar la propagación del cólera fue la educación para la salud. El desafío principal consistió en identificar y llevar a la práctica rápidos cambios conductuales en la población. Con este objetivo se contó con el apoyo de 22 educadores para la salud dentro del sistema estatal; dos en el Ministerio de Salud y veinte que cubrían 52\% de los 27 servicios de salud del país. Por otra parte, se contrataron profesores con experiencia en educación para la salud. Las líneas de intervención educativa estuvieron basadas en la formación de comités multiprofesionales de salud, diagnósticos educativos, coordinación con otros sectores estatales y privados, diseño de capacitación de equipos de salud, producción de material educativo, campañas de medios masivos de comunicación, efecto multiplicador a través de la capacitación de líderes, educación a grupos de riesgo y evaluación ${ }^{5}$. La entrega de información estaba dirigida a diferentes niveles: personas, familias y comunidades ${ }^{12}$.

El sistema de laboratorios de diagnóstico también operó en red. Todo laboratorio clínico y del ambiente público o privado que identificara $V$. cholerae debía notificar al ISP y enviar las cepas en forma inmediata al laboratorio de referencia, donde correspondía realizar su confirmación, testear la susceptibilidad antimicrobiana in vitro y efectuar su tipificación. Los resultados obtenidos, si eran negativos, se informaban semanalmente a los laboratorios locales, Ministerio de Salud y al Director del Hospital de donde procedía la cepa ${ }^{5,13}$. En caso de existir un hallazgo positivo, la comunicación era inmediata, en forma telefónica.

\section{Discusión}

El cólera se encuentra actualmente en la mayoría de los países de América Latina, representando un riesgo latente para nuestro país, por lo que se hace necesaria la constante alerta epidemiológica ${ }^{14}$. Sin duda, frente a la aparición de los primeros casos de cólera en el Perú en 1991, Chile activó su alarma, constituyendo un comité ad hoc nacional que dictó normas y planificó las primeras líneas de acción ${ }^{5,10}$. Se estableció una planificación estratégica de los servicios de salud, de norte a sur, estudiando las ventajas y desventajas que presentaba nuestro país para enfrentar la situación. Dentro de las ventajas existentes estaba la presencia de un sistema institucional de salud, la capacidad de reacción de los servicios de salud, la participación de la comunidad universitaria a través de académicos expertos y la participación comunitaria frente a las indicaciones entregadas por el Ministerio de Salud, además de la alta disponibilidad de agua potable en el área urbana. En cuanto a las desventajas, encontramos la falta de hábitos higiénicos arraigados en parte de la población, la contaminación de las aguas de mares y ríos y la baja cobertura de plantas de tratamiento de aguas servidas ${ }^{5}$.

El éxito de la campaña realizada en nuestro país se debió principalmente a la integración del sector público con el sector privado, lo que determinó una intervención oportuna, adecuada, eficiente y equilibrada ${ }^{5}$. Es importante mencionar que el cólera determina un impacto negativo en la economía, debido a las necesarias medidas restrictivas que es preciso incorporar en relación al comercio internacional, como fueron las restricciones impuestas a muchos países de América Latina, especialmente aquellos exportadores de alimentos ${ }^{10}$. En consecuencia, el cólera no es sólo un tema relacionado exclusivamente al sector salud, sino que es parte de un problema de Salud Pública, durante el cual salen a la luz pública las deficiencias en la infraestructura de saneamiento, principal responsable de que la enfermedad se difunda con mucha rapidez $z^{5,8,10}$. Hay que agregar que existen otros factores que impiden la erradicación del cólera, a saber, la persistencia de $V$. cholerae en el ambiente acuático, el incremento de la densidad poblacional, la inexistencia de una vacuna adecuada y protección limitada de la inmunidad natural, el desarrollo de tratamiento efectivo y la flexibilidad y variedades de las cepas del agente bacteriano ${ }^{15}$.

Por último, en la Figura 1 se puede observar la tendencia decreciente de los casos de cólera en los países de nuestra región durante el período 1991-2006. Los casos han descendido desde 400.000 a tan sólo 13 en el año 2006; no obstante ello, la mantención de un estado de 


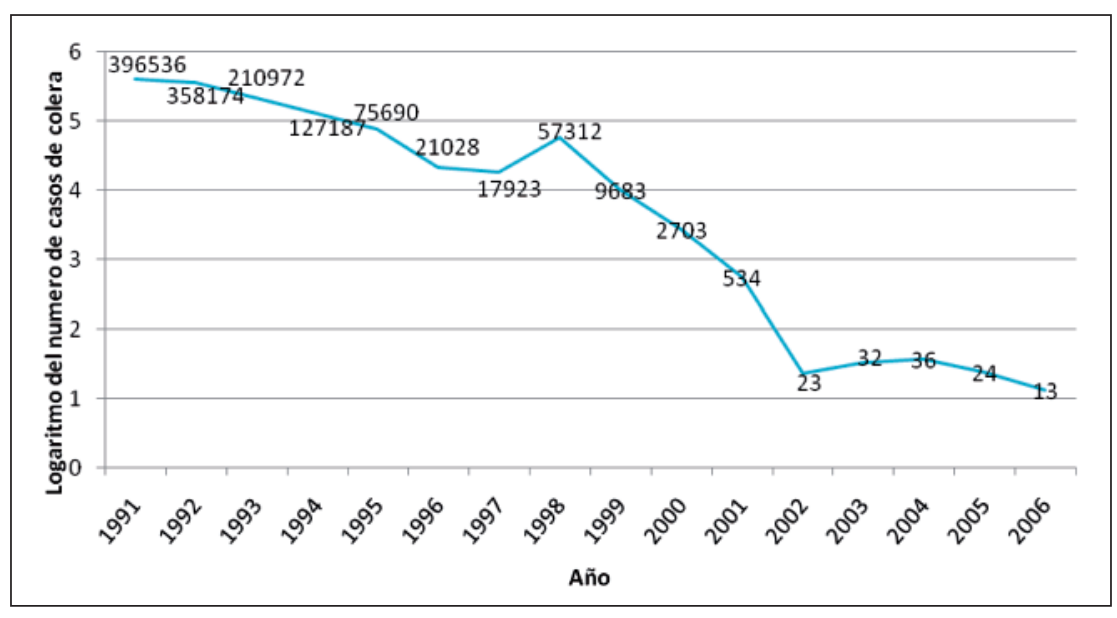

Figura 1. Total casos de cólera en la Américas. 1991-1996.

alerta debe ser permanente ${ }^{15}$. Destacamos la necesidad de implementar una red de vigilancia epidemiológica activa y definida que permita asistir a las zonas de mayor riesgo, que disminuya los costos de su implementación y que supervise y entregue información acerca de los agentes etiológicos causantes de infecciones intestinales, permitiendo que se lleven a cabo medidas de intervención específicas así como la evaluación de las actualmente existente $^{5,15}$

\section{Resumen}

Más de 700.000 casos y alrededor de 6.000 muertes se produjeron en la última epidemia de cólera registrada en América Latina, ocurrida en 1991. Esta se inició en el Perú y se propagó de país en país, afectando a la mayor parte de la región, incluyendo Chile. Comparado al Perú, la epidemia en Chile tuvo consecuencias menores debido a las medidas adoptadas por el Sistema Nacional de Servicios de Salud, en conjunto con otras entidades del Estado. Dentro de estas medidas destacan el establecimiento del Consejo Nacional de Salud, la planificación estratégica de los Servicios de Salud, el fortalecimiento de los Sistemas de Vigilancia Epidemiológica y de Laboratorios Clínicos y Ambientales, la educación de la población y las estrategias de prevención. La mantención de las medidas de sanidad ambiental y la colaboración de la población son fundamentales para evitar la aparición futura de la enfermedad.

\section{Referencias}

1.- Organización Mundial de la Salud (OMS). Epidemias mundiales e impacto del cólera. Disponible en: http://www.who.int/topics/cholera/impact/es/ index.html. (accedido 19 de mayo de 2006).

2.- Requena C, Reyes O, Reyes K, Rodríguez J, Zapata I. El brote epidémico del cólera en el Perú en la década de los noventa. Disponible en: http://www. monografías.com/trabajos16/colera-peru/colera-peru.shtml. (accedido 19 de mayo de 2006).

3.- Cordano A M. Enfermedades Infecciosas emergentes. Anales de la Universidad de Chile, 2000; VI serie $\mathrm{N}^{\mathrm{o}} 11$.

4.- Ministerio de Salud (MINSAL). El cólera en Chile. ¿Cómo enfrentó Chile a epidemia? Disponible en: http://www.minsal.cl/ici/info.asp?id=180. (accedido 22 de mayo de 2006).

5.- Jiménez J. El cólera en Chile. 1992. Ministerio de Salud, Chile.

6.- Guthmann J P. Epidemic cholera in Latin America: spread and routes of transmission.

J Trop Med Hyg 1995; 98 (6): 419-27.
7.- Olsvik O. The cholera epidemia in Latin America. Tidsskr Nor Laegeforen 1992; 112 (14); 1843-6.

8.- Medina E. Epidemic of cholera in Chile; 1991. Rev Méd Chile 1991; 119( 8): 943-56.

9.- Ministerio de Salud (MINSAL). Vigilancia Epidemiológica cólera. 1991. Ord. $\mathrm{N}^{\circ} 4 \mathrm{~A} / 735$.

10.- Ministerio de Salud (MINSAL). Informe sobre cólera. 1994.

11.- Ministerio de Salud (MINSAL). Vigilancia y control del cólera. 1998. Disponible en: http://www.epi.minsal.cl/epi/html/normas/circul/circular-colera. pdf. (accedido 23 de mayo de 2006).

12.- Ministerio de Salud (MINSAL). Orientaciones de educación y comunicación social para la prevención del cólera. 1991. Ord. No 4D/2964.

13.- Instituto de Salud Pública. Vigilancia de Vibrio cholera. Disponible en: http://www.ispch.cl. (accedido 23 de mayo de 2006).

14.- Situación de Salud Chile. Enfermedades entéricas. 1996.

15.- Organización Mundial de la Salud (OMS). Cólera. Región de las Américas, 1991-2002. Junio 2003. Disponible en: http://www.paho.org/spanish/ad/dpc/ cd/cholera-situacion91-02.pps. (accedido 19 de mayo de 2006). 